\title{
Efeito do ângulo do jato nas características técnicas de um canhão hidráulico
}

\author{
Giuliani do Prado', Lessandro C. Faria ${ }^{2}$, Henrique F. E. de Oliveira ${ }^{3}$ \& Alberto Colombo $^{4}$
}

\section{RESUMO}

Avaliaram-se os efeitos de diferentes ângulos de saída do jato de água de um canhão hidráulico, combinados com diferentes diâmetros de bocais e pressões de serviço, sobre o raio de alcance e perfil radial de distribuição de água. A caracterização técnica do canhão hidráulico foi realizada em bancada de ensaios de aspersores da Universidade Federal de Lavras, em Lavras, MG, totalizando 24 diferentes condições operacionais. O raio de alcance do aspersor foi estimado pelo ajuste de uma equação potencial em função do diâmetro do bocal (18 e $22 \mathrm{~mm})$, da pressão de serviço $(294,392$, 490 e $588 \mathrm{kPa})$ e do ângulo de lançamento do jato de água $\left(16,22\right.$ e $28^{\circ}$ ). Além disto, foi realizada uma análise percentual da distribuição do volume de água aplicado ao longo do raio de alcance do aspersor. As reduções no alcance horizontal do jato de água foram mais pronunciadas em condições de baixas pressões e para o ângulo de jato de $16^{\circ}$; ocorre uma redução no raio de alcance do aspersor de 3,4 a $4,0 \%$, a cada $3^{\circ}$ de redução do ângulo de lançamento de $28^{\circ}$; ângulos de lançamento do jato maiores que $22^{\circ}$, associados com pressões de serviço superiores a $392 \mathrm{kPa}$, resultam em maiores volumes de água aplicados entre 60 e $80 \%$ do raio de alcance do aspersor.

Palavras-chave: diâmetro do bocal, pressão de serviço, perfil radial

\section{Effect of trajectory angle on technical characteristics of a gun sprinkler}

\begin{abstract}
The effect of different trajectory angles of a gun sprinkler associated with different nozzle diameters and working pressures on the radius of throw and water distribution profile were assessed in this study. The technical characterization of the gun sprinkler was carried out at a sprinkler test bench of the Universidade Federal de Lavras, at Lavras, MG, for 24 different working conditions. In function of nozzle diameter (18 and $22 \mathrm{~mm}$ ), service pressure $\left(294,392,490\right.$ and $588 \mathrm{kPa}$ ) and trajectory angle $\left(16,22\right.$ and $\left.28^{\circ}\right)$, a potential equation was adjusted to estimate the radius of throw. Furthermore, along the radius of throw the percentage distribution of the amount of water applied was analysed. For low working pressures associated with trajectory angle of $16^{\circ}$, higher reductions were observed on the radius of throw; from the $28^{\circ}$ trajectory angle, for every $3^{\circ}$ drop of the trajectory angle the radius of throw is reduced by approximately 3.4 to $4.0 \%$; for trajectory angles higher than $22^{\circ}$ associated with working pressures higher than $392 \mathrm{kPa}$, the amount of water applied from the gun sprinkler is more between 60 and $80 \%$ of radius of throw.
\end{abstract}

Key words: nozzle diameter, working pressure, radial profile

DEA/UEM, CEP 87820-000, Cidade Gaúcha, PR. Fone: (44) 3675-1779. E-mail: gprado@uem.br

${ }^{2}$ CDTec/Eng. Hídrica/UFPel, CEP 96010-610, Pelotas, RS. Fone: (53) 3921-1400. E-mail: lessandro.faria@ufpel.edu.br

${ }^{3}$ DCA/IF Goiano, Rod. 154, Km 03, C.P. 51, CEP 76300-000, Ceres, GO. Fone: (62) 3307-7100. E-mail: henrique.fonseca@ifgoiano.edu.br

${ }^{4}$ DEG/UFLA, C.P. 3037, CEP 37200-000, Lavras, MG. Fone: (35) 3829-1388. E-mail: acolombo@ufla.com 


\section{INTRODUÇÃO}

Os sistemas de irrigação por aspersão revolucionaram o desenvolvimento da agricultura irrigada sendo muito difundidos em todo o mundo. De acordo com Pascal et al. (2006), os sistemas por aspersão com canhão hidráulico são de grande utilização pois permitem aplicações eficientes de água, com custos relativamente baixos.

Canhões hidráulicos se caracterizam por aplicar grandes quantidades de água sendo de suma importância que a água aplicada infiltre totalmente no ponto em que ela cai, evitando acumulação em terrenos planos e escoamento superficial em terrenos acidentados (Karney \& Podmore, 1984). Conforme Shull \& Dylla (1976), o efeito do acúmulo de água na superfície do terreno é mais acentuado em áreas com influência de vento, nas quais se formam picos de precipitação sendo a taxa de aplicação de água maior em determinados pontos e menor em outros.

Um planejamento da irrigação com uniformidades elevadas de aplicação de água e um manejo adequado do sistema, podem garantir maior rendimento da cultura além de reduzir o consumo de água e energia, acarretando em benefícios econômicos (Dechmi et al., 2004) e, consequentemente, minimizam os impactos negativos sobre o ambiente, ocasionados pela agricultura irrigada (Ortega et al., 2004).

De acordo com Mateos (1998) e Prado \& Colombo (2010), as características dos aspersores que afetam a uniformidade de aplicação de água são: o modelo, o número e tamanho de bocais, a pressão de serviço e o ângulo do jato de água do aspersor; além desses, fatores como a altura de instalação dos aspersores, o espaçamento e o tipo de arranjo dos aspersores no campo podem afetar a distribuição de água do equipamento. Faria et al. (2009) e Oliveira et al. (2009) afirmam que fatores não controláveis, como a velocidade e a direção do vento, têm grande influência na performance dos aspersores.

A existência de diferentes possibilidades de combinação entre pressão de serviço, diâmetros de bocais dos aspersores e a dificuldade de realizar ensaios de distribuição de água, principalmente em aspersores do tipo canhão hidráulico, dificultam que as empresas fabricantes de aspersores disponibilizem as características técnicas de distribuição de água dos mesmos em seus catálogos técnicos (Prado \& Colombo, 2009). Além disto, estudos desta magnitude são bastante escassos na literatura estando, muitas vezes, relacionados com aspersores não mais disponíveis no mercado, sendo raros os dados relacionados ao perfil de distribuição de água de aspersores em função da variação do ângulo de lançamento do jato de água.

$\mathrm{O}$ vento é fator relevante na eficiência da irrigação em sistemas de aspersão, pois influência na trajetória assumida pelo jato de água do aspersor (Granier et al., 2003; Smith et al., 2008). Desta forma, regulagens no ângulo de lançamento do jato de água do aspersor podem reduzir a deriva pelo vento e proporcionar uma eficiência melhor de irrigação. Conforme Bernuth (1988) encontra-se disponível, no mercado, uma ampla gama de aspersores com ângulos de lançamento do jato de água (entre 6 até $27^{\circ}$ ) e que o emprego de aspersores com ângulo de lançamento do jato de água menor pode reduzir o efeito do vento e manter a uniformidade de aplicação de água. Além do mais, a redução do ângulo de saída do jato de água pode ser útil para evitar obstáculos locais, tais como redes elétricas e estradas.

Em condições nulas de vento, Bilanski \& Kidder (1958) observaram que o aumento no ângulo de saída do jato de água entre 10 e $35^{\circ}$ (em intervalos de $5^{\circ}$ ), proporcionou um aumento no alcance do jato e redução na quantidade de água coletada no pico de máxima precipitação, sendo a razão deste decréscimo minimizada de acordo com o aumento na inclinação do ângulo. Conforme os mesmos autores, nas proximidades do aspersor foram mínimas as diferenças nas quantidades de água precipitada para os diferentes ângulos de saída do jato de água.

Tomazela (1996) observou, ao avaliar um canhão hidráulico operando em condições de vento com bocais de 16 x $6 \mathrm{~mm}$ e com ângulos de saída do jato de 18 a $30^{\circ}$ (em intervalos de $3^{\circ}$ ), que o ângulo de $24^{\circ}$ apresentou um pequeno acréscimo em termos de área molhada, apresentando melhor desempenho em termos da combinação entre área molhada e pressão de serviço.

A regulagem no ângulo de lançamento do jato de água de alguns canhões hidráulicos disponíveis no mercado nacional é uma realidade. Desta maneira, este estudo teve como objetivo avaliar os efeitos de diferentes ângulos de saída do jato de água de um canhão hidráulico, combinados com diferentes diâmetros de bocais e pressões de serviço, sob o raio de alcance e o perfil radial de distribuição de água do aspersor.

\section{Material e Métodos}

O trabalho foi realizado com um canhão hidráulico Komet ${ }^{\circledR}$, modelo Twin 140/Plus (Figura 1A), instalado em bancada de ensaios de aspersores do Laboratório de Hidráulica do Departamento de Engenharia na Universidade Federal de Lavras (DEG/UFLA), Lavras, MG. Este aspersor é um canhão hidráulico de reversão lenta, de giro proporcionado pelo impacto do braço oscilante sob o jato com flange de acoplamento de 2 $1 / 2$ ", oito possibilidades de bocais cônicos convergentes $(16,18$, $20,22,24,26,28$ e $30 \mathrm{~mm}$ ) e possibilidade de regulagem no ângulo de lançamento do jato de água de 10 até $28^{\circ}$ (Figura 1B).

$\mathrm{Na}$ condução do trabalho foram realizados ensaios para determinação das características técnicas do aspersor (vazão, raio de alcance e perfil radial de distribuição de água) em 24 condições operacionais distintas, obtidas pelas combinações dos bocais de 18 e $22 \mathrm{~mm}$ com as pressões de 294, 392, 490 e 588 $\mathrm{kPa}$ e os ângulos de lançamento do jato de água de 16,22 e $28^{\circ}$.

Os ensaios foram conduzidos nas primeiras horas da manhã ou no fim da tarde, de modo a evitar, conforme recomenda a norma ISO (1990), a ocorrência de ventos com velocidades superiores a $0,9 \mathrm{~m} \mathrm{~s}^{-1}$. A incidência de ventos foi monitorada com anemômetro totalizador de canecas, instalado a $2 \mathrm{~m}$ de altura em relação à superfície do solo. Na eventualidade da ocorrência de velocidades de ventos superiores ao valor prescrito na referida norma, os ensaios eram suspensos e seus resultados descartados.

Durante os ensaios o aspersor foi instalado em uma bancada experimental composta de uma campânula circular de alvenaria com raio de $1,5 \mathrm{~m}$ e abertura de $18^{\circ}$, que abriga o aspersor, e uma linha de coletores dispostos radialmente, em espaçamento variável, menor que $1 \mathrm{~m}$, que se estende até a distância de 70 
A.

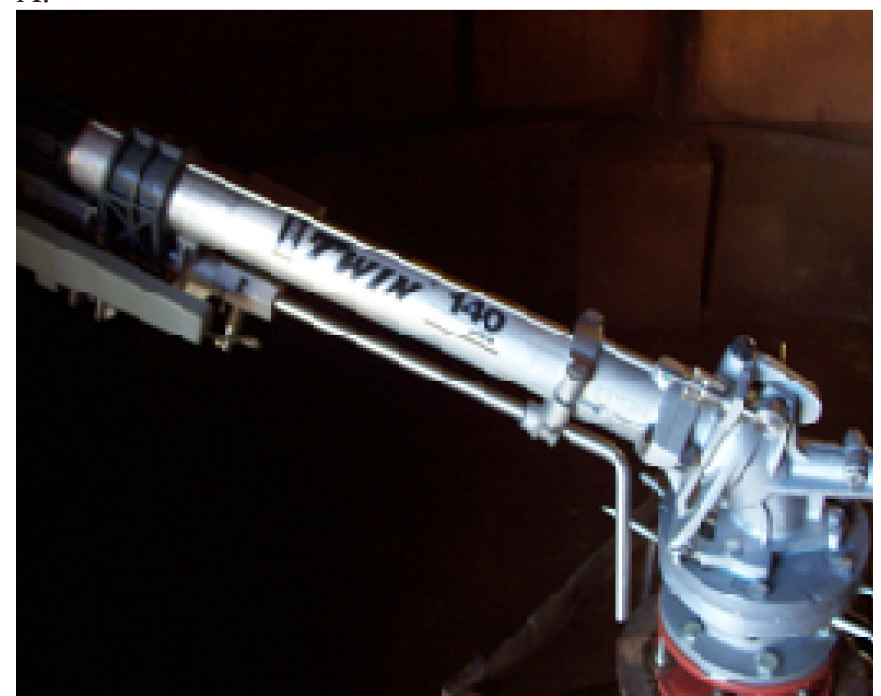

C.

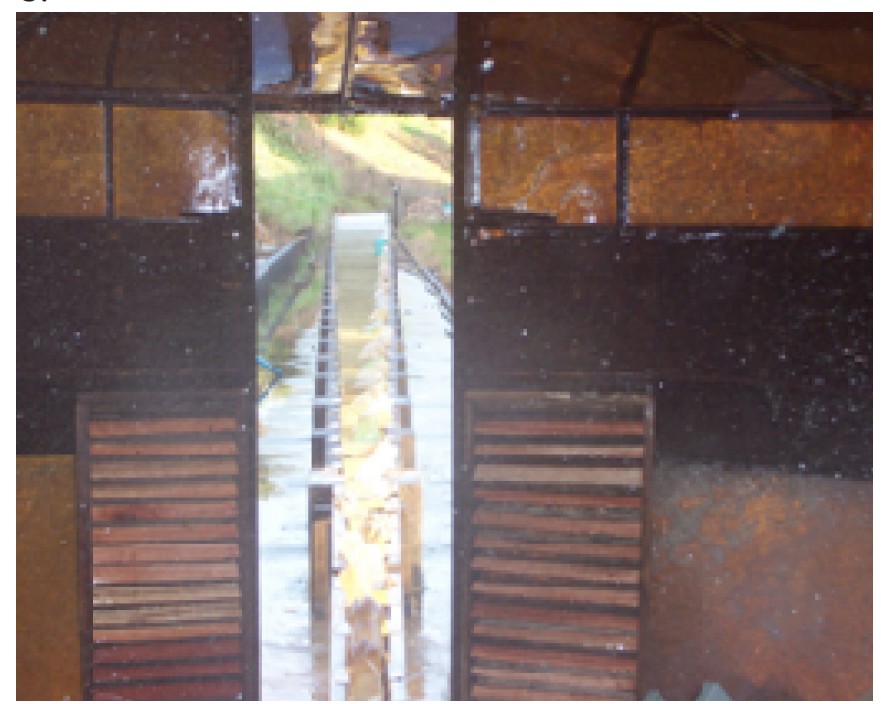

B.

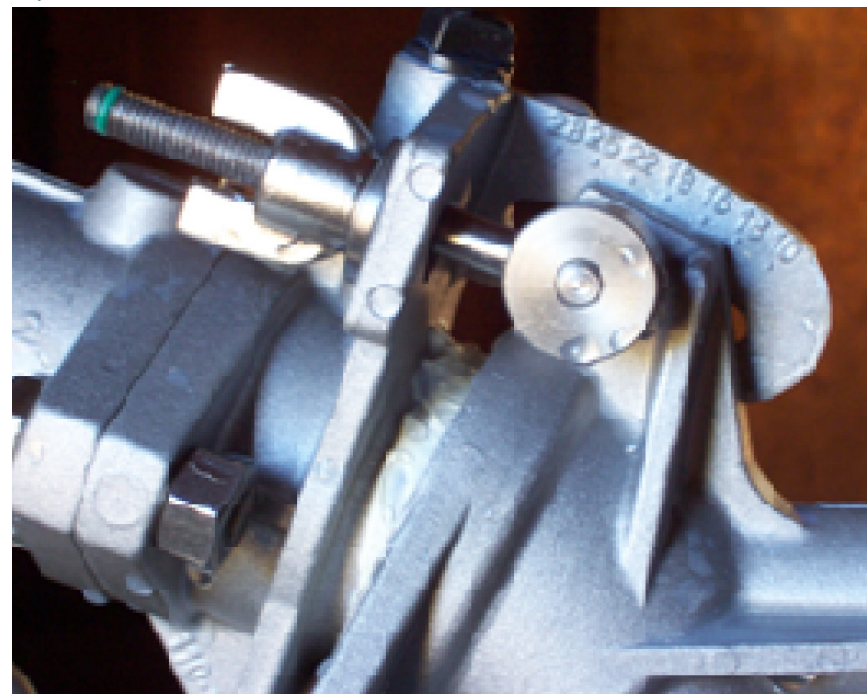

D.

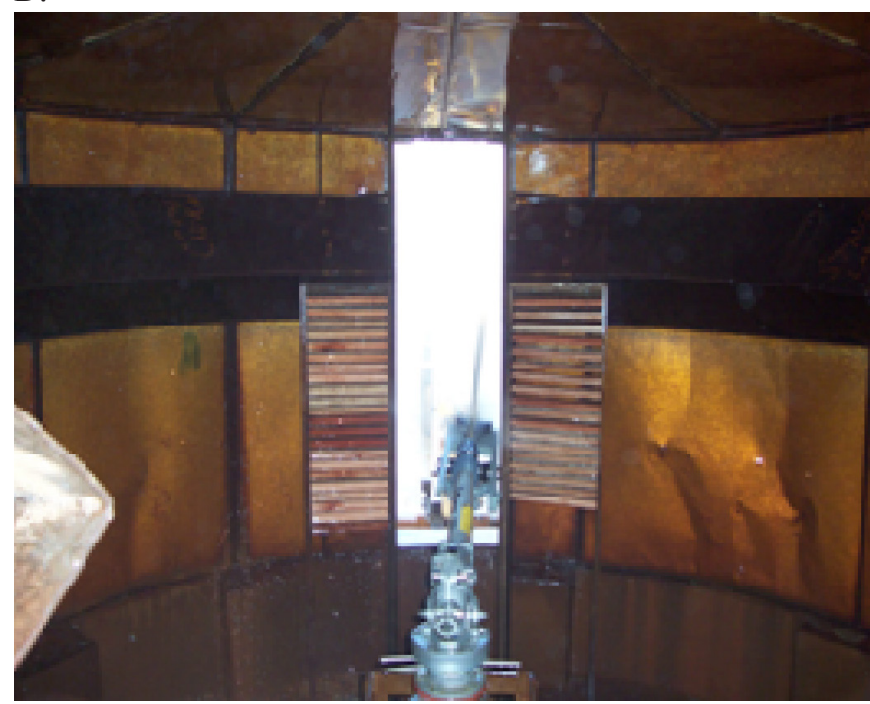

Figura 1. Canhão hidráulico Komet ${ }^{\circledR}$ - Twin 140/Plus (A); mecanismo de regulagem do ângulo de lançamento de água do canhão hidráulico (B); disposição dos coletores de água na bancada (C); ensaio de distribuição de água do canhão hidráulico (D)

m do centro da campânula (Figura 1C). Esta linha de coletores de água é constituída por 110 calhas com área de captação em formato retangular apresentando largura fixa de $0,20 \mathrm{~m}$ e comprimento variável, de modo a satisfazer um ângulo de abertura $1^{\circ} 50^{\prime}$, em relação ao centro da campânula. A altura do topo das calhas em relação ao centro do bocal principal foi de $0,59,0,65$ e $0,71 \mathrm{~m}$, respectivamente, para os ensaios com ângulo de lançamento do jato de água de 16,22 e $28^{\circ}$.

As avaliações eram iniciadas após estabilizar a pressão de serviço medida na base do aspersor, com manômetro digital alocado externamente à campânula e em mesmo plano vertical do bocal do aspersor; fixada a pressão de serviço, liberava-se o braço oscilante e o aspersor iniciava seu giro setorial de $240^{\circ}$ no interior da campânula, pelo tempo de 40 min (Figura 1D); durante os ensaios os valores de vazão e pressão eram monitorados em intervalos de $10 \mathrm{~min}$ e, ao final de cada ensaio, eram realizados os registros dos volumes de água precipitados em cada coletor para determinação do raio de alcance do aspersor e do perfil radial de distribuição de água.
Ao término de cada ensaio o valor de vazão determinado pelo medidor eletromagnético (precisão $\pm 0,01 \mathrm{~m}^{3} \mathrm{~h}^{-1}$ ) foi comparado com o valor de vazão correspondente ao giro completo do perfil radial de distribuição de água determinado em ensaio (Seginer et al., 1992; Gat \& Molle, 2000), que é calculado pela Eq. 1:

$$
\begin{aligned}
Q_{P} & =\frac{2 \pi}{1000} \times \int_{r=0}^{r=R}\left[i_{j}\left(r_{j}\right)\right] \times r_{j} \times d_{r}=\frac{2 \pi}{1000} \times\left[\frac{i_{1} \times\left(r_{1}\right)^{2}}{3}+\right. \\
& \left.+\sum_{j=2}^{n}\left[\frac{a_{j}}{2} \times\left[\left(r_{j}\right)^{2}-\left(r_{j-1}\right)^{2}\right]+\frac{b_{j}}{3} \times\left[\left(r_{j}\right)^{3}-\left(r_{j-1}\right)^{3}\right]\right]\right]
\end{aligned}
$$

em que:

$Q_{p} \quad$ - vazão correspondente ao giro completo do perfil radial, $\mathrm{m}^{3} \mathrm{~h}^{-1}$

$\mathrm{i}_{\text {. }}(\mathrm{r})$ - intensidade de precipitação observada, em função da distância radial ao aspersor, em um coletor de índice $\mathrm{j}, \mathrm{mm} \mathrm{h}^{-1}$

$\mathrm{R} \quad$ - raio de alcance do aspersor, $\mathrm{m}$ 
$r_{j} \quad$ - distância radial de cada coletor de índice j em relação ao aspersor, $\mathrm{m}$

n - número de coletores que receberam água

$a_{j}$ e $b_{j}$ - coeficientes da equação linear ajustada aos valores de intensidade de precipitação e distância radial ao aspersor observados entre dois coletores consecutivos, que foram calculados através das Eqs. 2 e 3:

$$
\begin{gathered}
a_{j}=i_{j-1}-r_{j-1} \times b_{j} \\
b j=\frac{i_{j}-i_{j-1}}{r_{j}-r_{j-1}}
\end{gathered}
$$

em que: $2 \leq \mathrm{j} \leq \mathrm{n}$

Nos casos em que, a diferença entre os valores de vazão calculados pela Eq. 1 e determinados com o medidor eletromagnético diferiram em $10 \%$, os ensaios eram repetidos até se chegar a uma diferença menor que 10\% (Prado \& Colombo, 2005). Nos demais casos (diferença menor que 10\%), os valores observados de intensidade de precipitação foram corrigidos pela relação entre as duas vazões (Eq. 4):

$$
\mathrm{ic}_{\mathrm{j}}=\mathrm{i}_{\mathrm{j}} \frac{\mathrm{Q}}{\mathrm{Q}_{\mathrm{p}}}
$$

em que:

ic ${ }_{j}$ - valor corrigido da intensidade de precipitação no coletor de índice $\mathrm{j}, \mathrm{mm} \mathrm{h}^{-1}$

$\mathrm{Q}$ - vazão do aspersor, $\mathrm{m}^{3} \mathrm{~h}^{-1}$

Para permitir uma análise mais completa da influência do ângulo de lançamento do jato, sob os valores de intensidade de aplicação de água do perfil radial, foi também determinada para cada ensaio, a porcentagem da vazão total de água aplicada (Eq. 4) ao longo de cinco anéis concêntricos ao redor do aspersor, com espessura correspondente a $20 \%$ do raio total de alcance (0 a $0,2 \mathrm{R} ; 0,2 \mathrm{R}$ a $0,4 \mathrm{R} ; \ldots . .0,8 \mathrm{R}$ a R), dado pela Eq. 5:

$$
\mathrm{Q} \%_{\mathrm{k}}=\frac{\mathrm{Q}_{\mathrm{k}}}{\mathrm{Q}} \times 100
$$

em que:

$\mathrm{Q} \%{ }_{\mathrm{k}}$ - percentagem da vazão total do aspersor aplicada no anel de índice $\mathrm{k}(1 \leq \mathrm{k} \leq 5)$

$\mathrm{Q}_{\mathrm{k}} \quad$ - vazão aplicada pelo aspersor no anel de índice $\mathrm{k}, \mathrm{m}^{3} \mathrm{~h}^{-1}$

O procedimento de cálculo das vazões $Q_{k}$ foi semelhante ao utilizado no cálculo da vazão total do aspersor (Eq.1).

A adequação dos pares de valores de vazão versus pressão de serviço determinados nos ensaios, para as diferentes condições operacionais do aspersor, foi avaliada em termos do grau de ajuste dos valores medidos ao modelo empírico proposto por Solomon \& Bezdek (1980) para canhões hidráulicos (Eq. 6):

$$
\mathrm{Q}=\mathrm{a}_{1} \times \mathrm{b}^{\mathrm{a}_{2}} \mathrm{p}^{\mathrm{a}_{3}}
$$

em que:

b - bocal do aspersor, $\mathrm{mm}$

$\mathrm{p} \quad$ - pressão de serviço do aspersor, $\mathrm{kPa}$

$a_{1}, a_{2}$ e $a_{3}$ - parâmetros de ajuste da equação

No caso dos valores de raio de alcance, foi introduzida uma modificação no modelo empírico proposto por Solomon \& Bezdek (1980), que permitiu a inclusão do valor do ângulo de lançamento do jato na expressão que já considerava o bocal e a pressão de serviço do aspersor (Eq. 7):

$$
\mathrm{R}=\mathrm{a}_{4} \times(\alpha \times \mathrm{b})^{\mathrm{a}_{5}} \times \mathrm{p}^{\mathrm{a}_{6}}
$$

em que:

$\alpha \quad$ - ângulo de lançamento do jato de água, graus

$a_{4}, a_{5}$ e $a_{6}-$ parâmetros de ajuste da equação

Em relação ao raio de alcance obtido com o ângulo de lançamento do jato de água de $28^{\circ}$, para uma dada pressão de serviço (p), foi calculado o decréscimo no raio de alcance com a redução do ângulo de lançamento do jato de água do aspersor pela Eq. 8:

$$
\mathrm{DR}_{(\alpha, \mathrm{p})}=\left(\frac{\mathrm{R}_{(\alpha, \mathrm{p})}-\mathrm{R}_{\left(28^{\circ}, \mathrm{p}\right)}}{\mathrm{R}_{\left(28^{\circ}, \mathrm{p}\right)}}\right) \times 100=\left[\left(\frac{\alpha}{28^{\circ}}\right)^{\mathrm{a}_{5}}-1\right] \times 100
$$

em que:

$\mathrm{DR}_{(\alpha, \mathrm{p})}$ - decréscimo no raio de alcance do aspersores, \%

$\mathrm{R}_{(\alpha, \mathrm{p})}$ - raio de alcance do aspersor para ângulo do jato de água $(\alpha)$ e pressão de serviço $(\mathrm{p}), \mathrm{m}$

$\mathrm{R}_{\left(28^{\circ}, \mathrm{p}\right)}$ - raio de alcance do aspersor para ângulo do jato de água de $28^{\circ}$ e pressão de serviço $(\mathrm{p}), \mathrm{m}$.

\section{Resultados e Discussão}

A relação entre os valores de vazão de descarga do canhão hidráulico observados nos ensaios de laboratório e os valores de vazão obtidos por meio da Eq. 6 e a relação entre os valores de raio de alcance observados nos ensaios e obtidos pela Eq. 7, podem ser observados nas Figuras 2 e 3, respectivamente.

Os pares de valores de vazão (Figura 2) e de raio de alcance (Figura 3) estão bem concentrados ao redor da reta $1: 1$, indicando um bom ajuste, evidenciado também pelo alto valor do coeficiente de determinação $\left(\mathrm{R}^{2}\right)$, sendo os valores dos parâmetros de ajuste da equação de vazão (Eq. 6) e da equação de raio de alcance (Eq. 7) observados na Tabela 1.

$\mathrm{Na}$ Figura 4 são apresentadas as curvas de raio de alcance para os bocais de $18 \mathrm{~mm}$ e $22 \mathrm{~mm}$, em função da pressão de serviço do aspersor. Verifica-se, nesta figura, um comportamento característico de aspersores que, ao promover incrementos na pressão de serviço, ocorre um incremento no raio de alcance. Este comportamento para algumas condições operacionais de bocais e pressão de serviço pode não ser tão pronunciado, como para o canhão hidráulico avaliado por Prado \& Colombo (2007). Também na Figura 4 se observa que a redução do ângulo de lançamento do jato proporciona uma redução do 


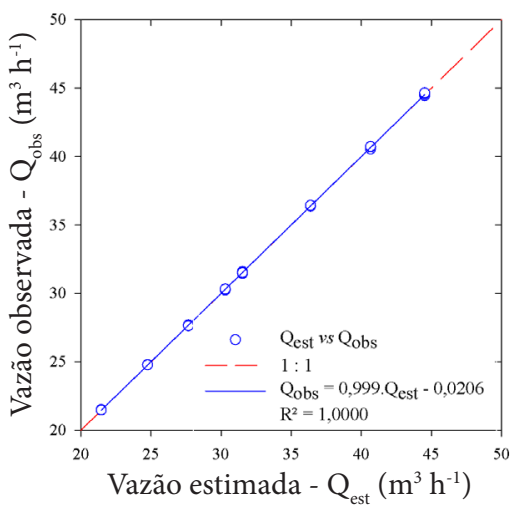

Figura 2. Valores de vazão do canhão hidráulico obtidos em ensaios $\left(Q_{\text {obs }}\right)$ versus valores de vazão estimados $\left(\mathrm{Q}_{\mathrm{es}}\right)$

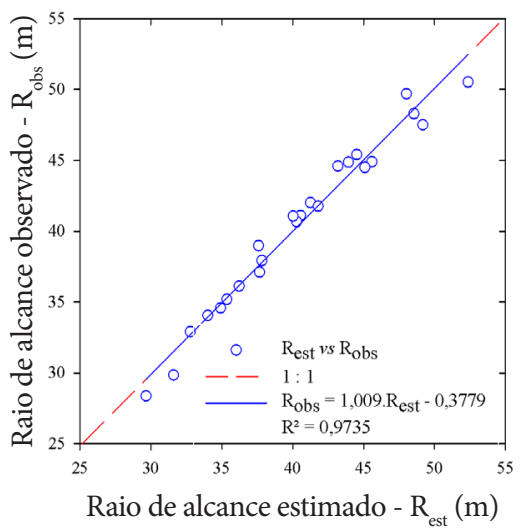

Figura 3. Valores de raio de alcance do canhão hidráulico obtidos em ensaios $\left(R_{\text {obs }}\right)$ versus valores de raio de alcance estimados $\left(R_{\text {est }}\right)$

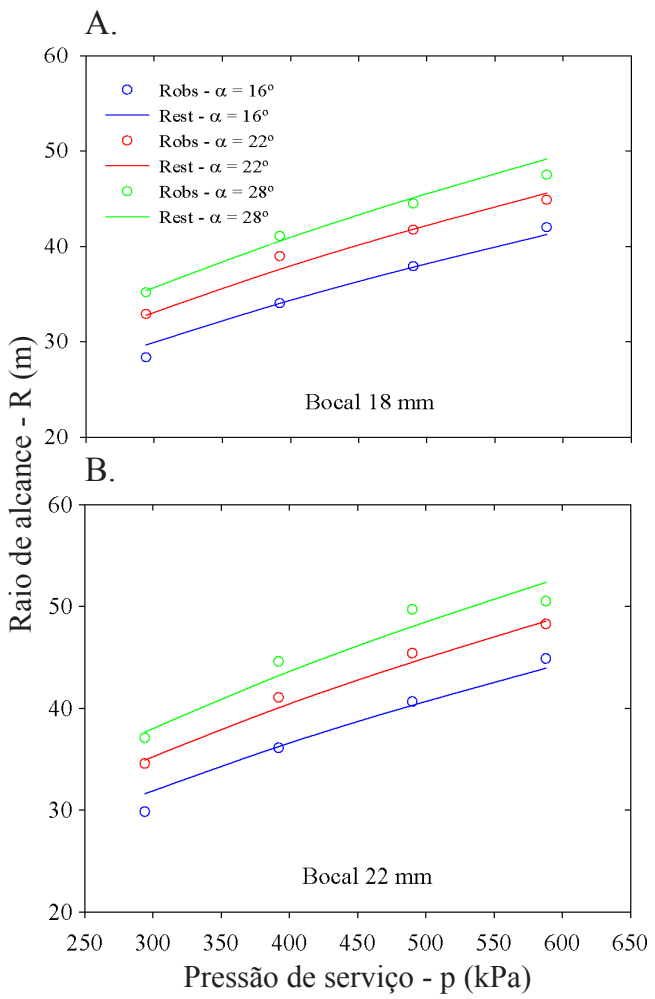

Figura 4. Efeito do ângulo do jato no raio de alcance do canhão hidráulico Komet ${ }^{\circledR}$ - Twin 140/Plus
Tabela 1. Parâmetros de ajuste da equação de vazão e do raio de alcance do canhão hidráulico Komet ${ }^{\circledR}$ Twin 140/Plus

\begin{tabular}{|c|c|c|c|}
\hline \multicolumn{2}{|c|}{$\begin{array}{l}\text { Parâmetros de ajuste da vazão } \\
\left(\mathrm{Q} \text { em } \mathrm{m}^{3} \mathrm{~h}^{-1}\right)\end{array}$} & \multicolumn{2}{|c|}{$\begin{array}{l}\text { Parâmetros de ajuste do raio de } \\
\text { alcance (R em } \mathrm{m})\end{array}$} \\
\hline a1 & 0,00494 & a4 & 0,33696 \\
\hline a2 & 1,91910 & a5 & 0,31369 \\
\hline a3 & 0,49796 & $a 6$ & 0,47536 \\
\hline
\end{tabular}

raio de alcance do canhão hidráulico. Seginer et al. (1992) observaram este mesmo comportamento para aspersores de pequeno e médio portes.

O decréscimo no raio de alcance do aspersor em função da redução do ângulo de lançamento do jato de água de $28^{\circ}$ para ângulos menores, é apresentado na Figura 5. Ao reduzir o ângulo de lançamento do jato de água do aspersor o mesmo apresenta reduções crescentes no raio de alcance; com uma redução do ângulo de lançamento de jato de água de 28 para $16^{\circ}$ há um decréscimo no raio de alcance do aspersor de $-16 \%$; também o decréscimo no raio de alcance do aspersor se acentua com a redução do ângulo de lançamento do jato de água do aspersor; ao reduzir o ângulo do jato de $28^{\circ}$ para $27^{\circ}$ ocorre uma redução de $-1,1 \%$ no raio de alcance do aspersor; entretanto, ao reduzir o ângulo do jato de água de 17 para $16^{\circ}$ a redução no raio de alcance do aspersor é de $-1,6 \%$.

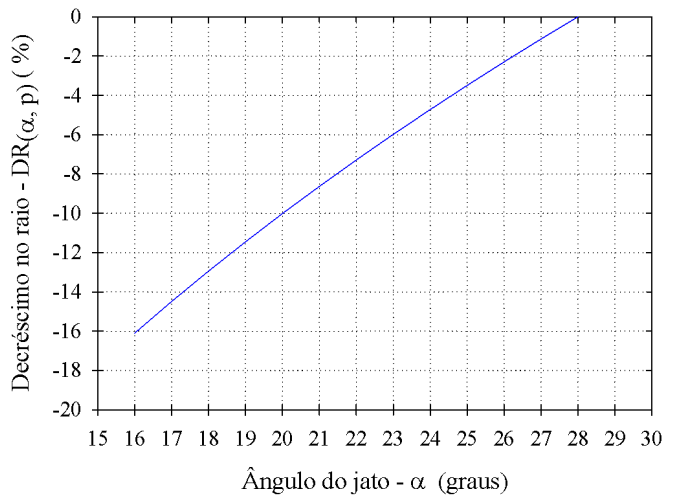

Figura 5. Variação do raio de alcance do canhão hidráulico Komet ${ }^{\circledR}$ - Twin 140/Plus em função de seu ângulo de lançamento do jato de água

No catálogo técnico do canhão hidráulico Komet ${ }^{\circledR}$, modelo Twin 140/Plus, o fabricante faz uma recomendação de redução do raio de alcance do aspersor de 3 a $4 \%$, a cada $3^{\circ}$ que se baixe o ângulo de lançamento do jato de água de $24^{\circ}$. Considerando as variações no raio de alcance do aspersor em função do ângulo de lançamento do jato de água, apresentadas na Figura 5, é possível observar uma redução no raio de alcance de 3,4 a $4,0 \%$ a cada $3^{\circ}$ baixando o ângulo de lançamento do jato de água para $28^{\circ}$.

Na Figura 6 são apresentados os perfis radias de distribuição de água do canhão hidráulico operando com bocais de 18 e 22 mm, pressões de serviço de 294, 392, 490 e $588 \mathrm{kPa}$ e ângulos de saída do jato de água de 16,22 e $28^{\circ}$. O comportamento observado na Figura 6 está de acordo com o obtido por Bilanski \& Kidder (1958), ou seja, o aumento no ângulo de saída do jato de água ocasionou um aumento no raio de alcance do aspersor e redução na taxa de aplicação de água na extremidade final do perfil radial 
de distribuição de água; além disto, observou-se, com o aumento da pressão de serviço, uma diminuição do acúmulo de aplicação de água na extremidade final dos perfis radiais de distribuição de água estando este comportamento de acordo com o previsto por Christiansen (1942) e Keller \& Bliesner (1990).

A redução no ângulo de lançamento do jato de água associada com baixas pressões de serviço do aspersor, gera um baixo grau de pulverização do jato de água com um pico de aplicação de água na extremidade final do perfil radial de distribuição de água (Figura 6). Segundo Prado et al. (2008), condições operacionais que proporcionem formas geométricas de perfil radial com um pico de aplicação de água na extremidade final do perfil radial do aspersor devem ser evitadas tanto para arranjos retangulares como para arranjos triangulares de aspersores operando em sistemas fixos de irrigação por aspersão. Para sistemas autopropelidos de irrigação, Prado \& Colombo (2007) e Prado
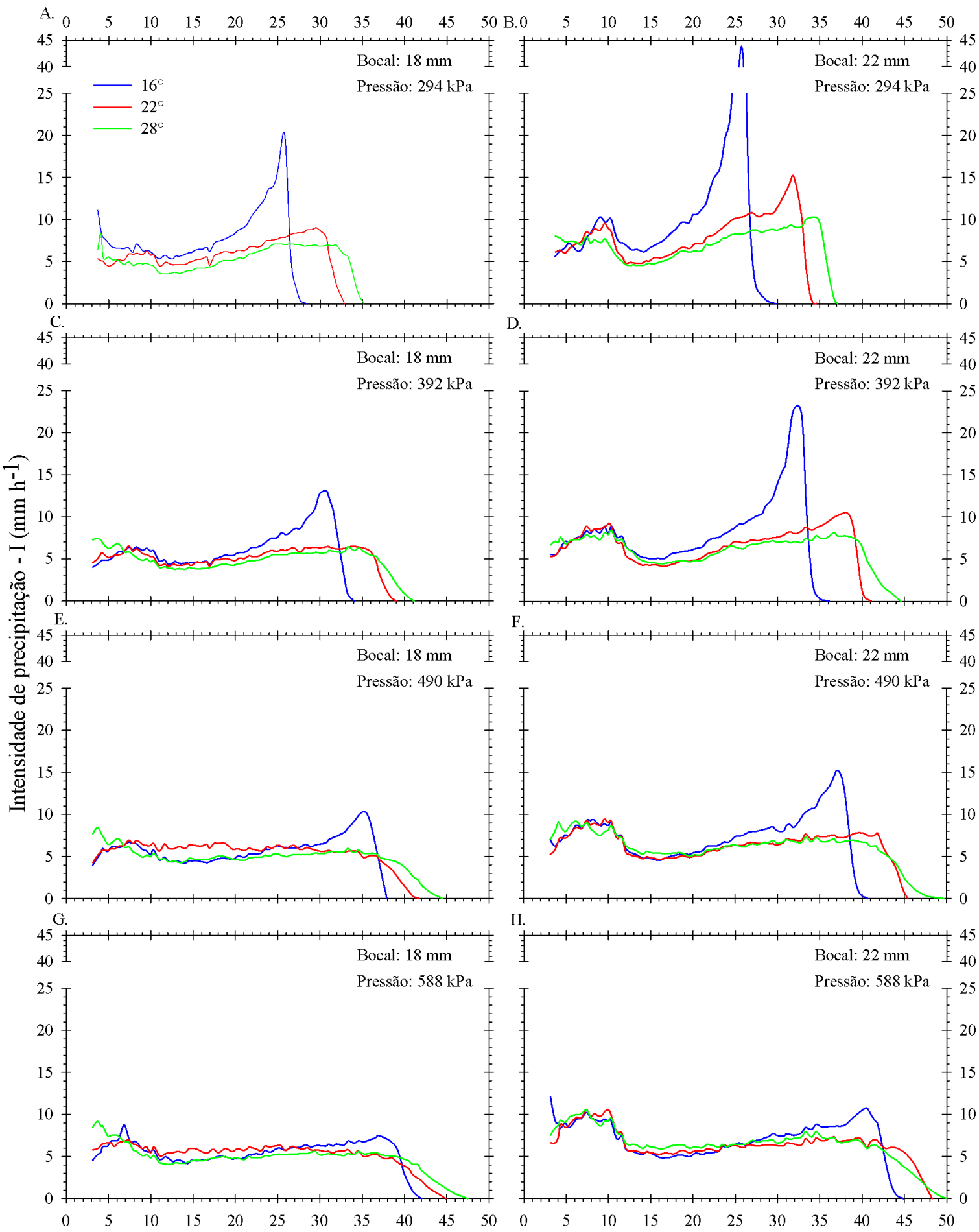

D
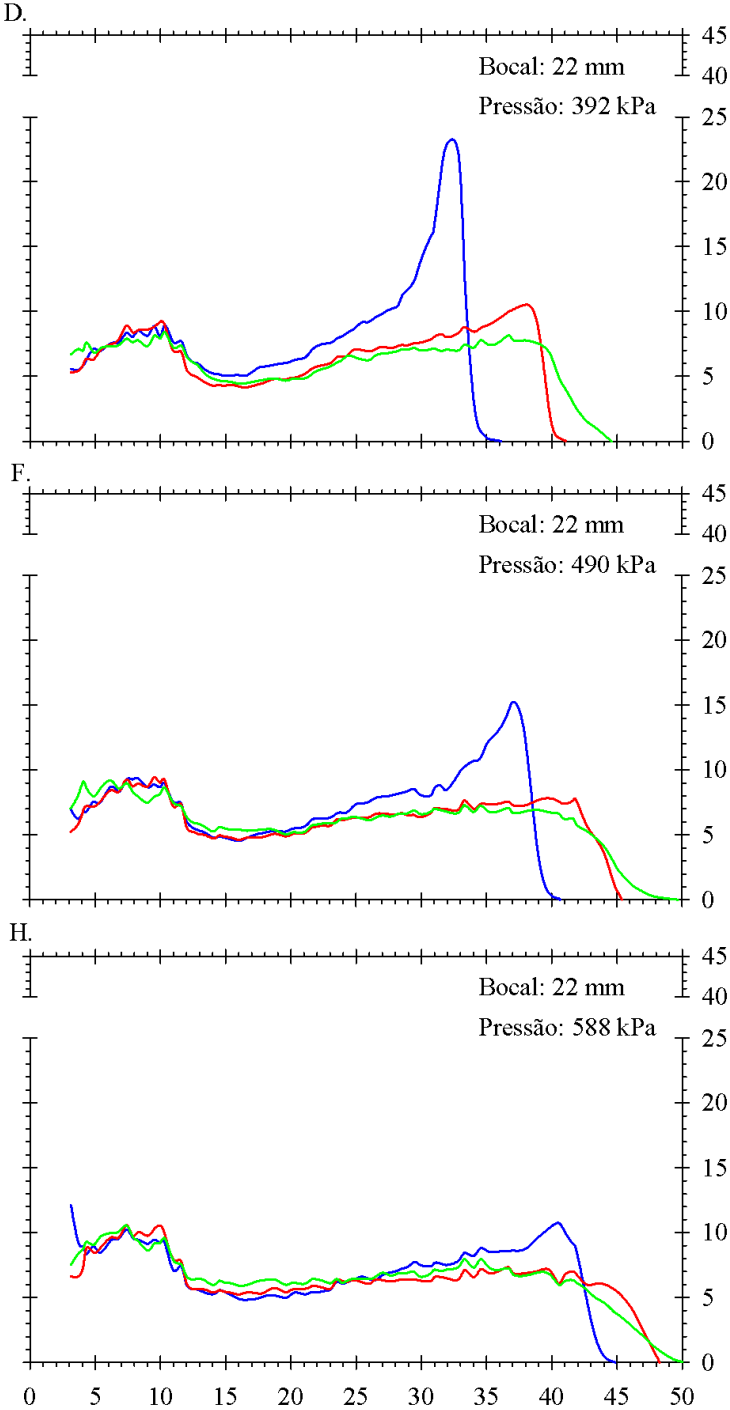

Distância - d (m)

Figura 6. Efeito do ângulo de lançamento do jato de água no perfil radial de distribuição de água do canhão hidráulico Komet $^{\circledR}$ - Twin 140/Plus 
et al. (2007) observaram baixos coeficientes de uniformidade de Christiansen para condições operacionais do aspersor que apresentaram perfis radiais com um pico de aplicação de água na extremidade final do raio de alcance do aspersor.

De acordo com as formas geométricas assumidas pelos perfis radiais teóricos apresentados por Christiansen (1942), os perfis radiais de distribuição de água do aspersor Komet ${ }^{\circledR}$, modelo Twin 140/Plus (Figura 6) que não apresentaram picos
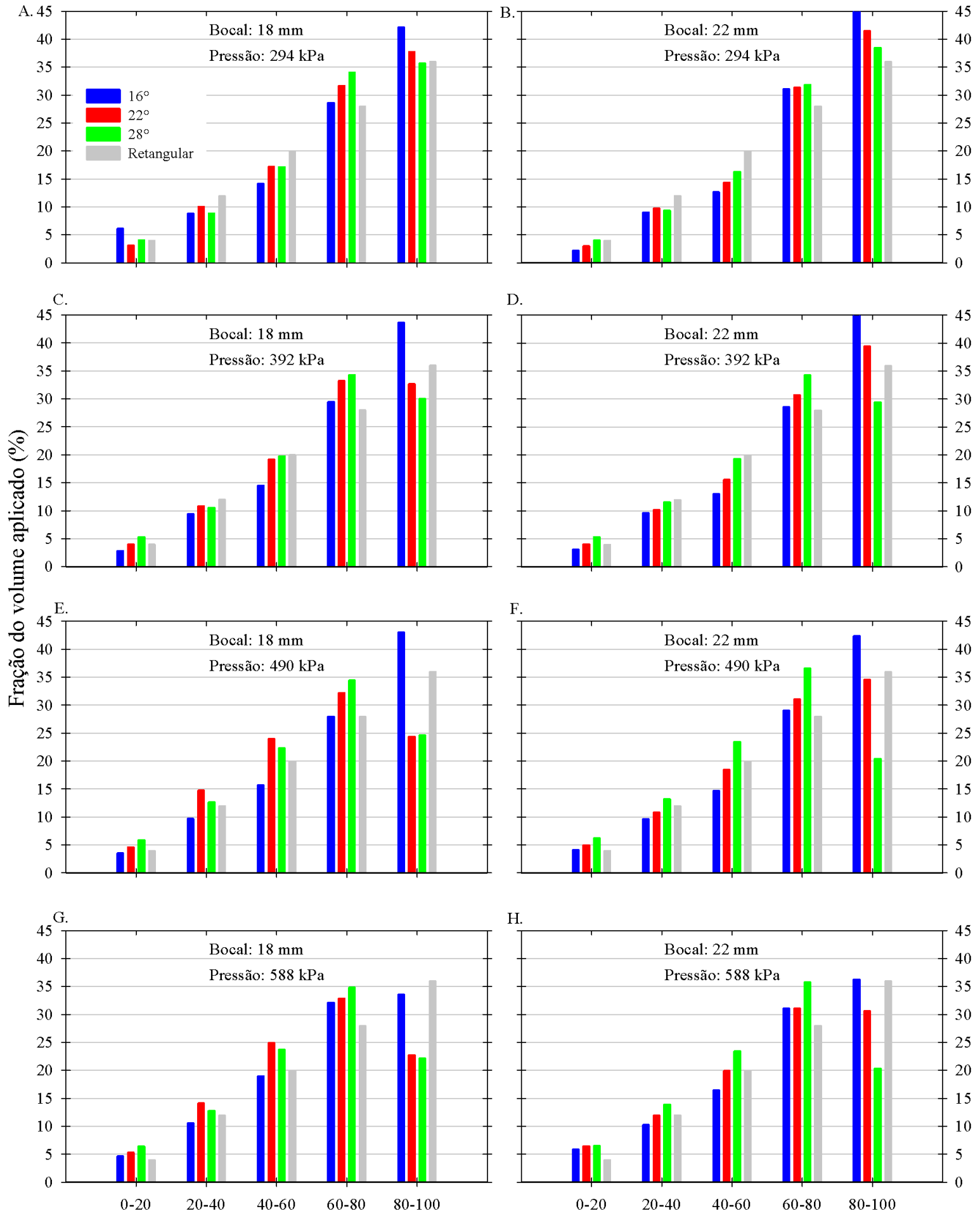

Fração do raio de alcance (\%)

Figura 7. Fração do volume de água aplicada ao longo do raio de alcance pelo canhão hidráulico Komet $^{\circledR}$ - Twin 140/Plus 
qual se observa que para um perfil radial teórico com formato geométrico retangular (perfil $\mathrm{F}$ de Christiansen), o volume de água ao longo do raio de alcance do aspersor aumenta proporcionalmente com o incremento da área molhada pelo aspersor. Este mesmo comportamento foi verificado para todas as condições operacionais de bocais do aspersor operando nas quatro diferentes pressões de serviço e com um ângulo de lançamento do jato de água de $16^{\circ}$ (Figura 7).

Para o ângulo de lançamento do jato de água de $22^{\circ}$ na pressão de $292 \mathrm{kPa}$, independente do bocal do aspersor e para o bocal de $22 \mathrm{~mm}$ operando sob a pressão de $392 \mathrm{kPa}$, o volume de água aplicado pelo aspersor foi crescente ao longo da fração do raio de alcance do jato (Figuras 7A, 7B e 7D). Entretanto, com o incremento da pressão de serviço do aspersor maior volume de água aplicada foi observado a uma distância compreendida entre 60 e $80 \%$ do raio de alcance do aspersor.

Os maiores volumes de água aplicados ao longo do raio de alcance do aspersor operando com um ângulo de lançamento do jato de água de $28^{\circ}$ e pressões de serviço superiores a 392 $\mathrm{kPa}$, independente do bocal do aspersor, foram observados a uma distância compreendida entre 60 e $80 \%$ do raio de alcance do aspersor. Para efeito de comparação do canhão hidráulico estudado e um microaspersor, Conceição \& Coelho (2004) observaram, para as diferentes condições operacionais, que os maiores volumes de água aplicados ao longo do perfil de distribuição de água estão localizados a uma distância compreendida entre 50 e $80 \%$ do raio de alcance.

Esses resultados indicam que o emprego de baixos ângulos de lançamento do jato de água pode prejudicar a aplicação de água pelo aspersor, porém é importante ressaltar que em condições adversas de vento a redução no ângulo de lançamento do jato de água pode representar um incremento na eficiência da irrigação com canhões hidráulicos.

\section{Conclusões}

1. Variações no raio de alcance são mais pronunciadas em condições de baixas pressões de serviço e para ângulos de jato menores, independente do bocal do aspersor.

2. Um decréscimo no raio de alcance do aspersor de 3,4 a $4 \%$ pode ser empregado a cada $3^{\circ}$ em que se reduz o ângulo de lançamento do jato de água de $28^{\circ}$.

3. Ângulos de lançamento do jato de água maiores que $22^{\circ}$ associados com a pressão de serviço superiores a $392 \mathrm{kPa}$, geram maiores volumes de água aplicada a uma distância compreendida entre 60 e $80 \%$ do raio de alcance do aspersor.

\section{Literatura Citada}

Bernuth, R. D. Effect of trajectory angle on performance of sprinklers in wind. Journal of Irrigation and Drainage Engineering, v.114, p.579-587, 1988.

Bilanski, W.; Kidder, E. H. Factors that affect the distribution of water from a medium-pressure rotary irrigation sprinkler. Transactions of the American Society of Agricultural Engineers, v.1, p.10-28, 1958.

Christiansen, J. E. Irrigation by sprinkling. Berkeley: California Agricultural Station, 1942. 124p. Bulletin, 670
Conceição, M. A. F.; Coelho, R. D. Distribuição do volume de água aplicado pelo microaspersor DAN 2001. Irriga, v.9, p.289-295, 2004.

Dechmi, F.; Playán, E.; Cavero, J.; Martínez-Cob, A.; Faci, J. M. Coupled crop and solid set sprinkler simulation model. I: Model development. Journal of Irrigation and Drainage Engineering, v.130, p.499-510, 2004.

Faria, L. C.; Colombo, A.; Oliveira, H. F. E.; Prado, G. Simulação da uniformidade da irrigação de sistemas convencionais de aspersão operando sob diferentes condições de vento. Engenharia Agrícola, v.29, p.19-27, 2009.

Gat, Y. L.; Molle, B. Model of water application under pivot sprinkler. I: Theoretical grounds. Journal of Irrigation and Drainage Engineering, v.126, p.343-347, 2000.

Granier, J.; Molle, B.; Deumier, J. M. IRRIPARC-Part 1: Modeling spatial water distribution under a sprinkler in windy conditions. In: European Regional Conference of the International Commission on Irrigation and Drainage, 20, 2003, Montpellier. Anais.... Montpellier: AFEID, 2003. CD-Rom

ISO - International Organization for Standardization. ISO 7749-2. Irrigation equipment - Rotating sprinklers - Part 2: Uniformity of distribution and test methods. Switzerland: ISO, 1990. 6p.

Karney, B. W.; Podmore, T. H. Performance of stationary gun irrigation system. Journal of Irrigation and Drainage Engineering, v.110, p.75-87, 1984.

Keller, J.; Bliesner, R. D. Sprinkle and trickle irrigation. New York: van Nostrand Reinhold, 1990. 652p.

Mateos, L. Assessing whole-field uniformity of stationary sprinkler irrigation systems. Irrigation Science, v.18, p.7381, 1998.

Oliveira, H. F. E.; Colombo, A.; Faria, L. C. Modelagem dos efeitos do vento sobre as dimensões do alcance do jato de um canhão hidráulico. Revista Brasileira de Engenharia Agrícola e Ambiental, v.13, p.818-824, 2009.

Ortega, J. F. A.; Tarjuelo, J. M. M.; de Juan, J. A. V.; Carrion, P. P. Uniformity distribution and its economic effect on irrigation management in semiarid zones. Journal of Irrigation and Drainage Engineering, v.130, p.257-347, 2004.

Pascal, M.; Kadem, N.; Tchiftchibachian, A. Investigation of the influence of sprinkler fins and dissolved air on jet flow. Journal of Irrigation and Drainage Engineering, v.132, p.41-46, 2006.

Prado, G.; Colombo, A. Caracterização técnica do aspersor PLONA-RL300. Irriga, v.10, p.53-63, 2005.

Prado, G.; Colombo, A. Análise da uniformidade de aplicação de água pelo aspersor PLONA-RL250 em sistemas autopropelidos de irrigação. Irriga, v.12, p.249-262, 2007.

Prado, G.; Colombo, A. Composição de perfis radiais de distribuição de água de aspersores. Irriga, v.14, p.41-53, 2009.

Prado, G.; Colombo, A. Distribuição espacial da água aplicada por equipamentos autopropelidos de irrigação - Parte I: Modelagem com o Simulasoft. Irriga, v.15, p.51-62, 2010.

Prado, G.; Colombo, A; Barreto, A. C; Matos, F. A. de; Ferreira Júnior, J. J. Uniformidade de aplicação de água pelo aspersor PLONA-RL250 em sistemas estacionários de irrigação. Irriga, v.13, p.220-234, 2008. 
Prado, G.; Colombo, A; Biagioni, P. F. Análise da uniformidade de aplicação de água pelo aspersor PLONA-RL400 em sistemas autopropelidos de irrigação. Revista de Engenharia, v.27, p.346-353, 2007.

Seginer, I.; Kantz, D.; Nir, D.; Bernuth, R. D. von. Indoor measurement of single-radius sprinkler patterns. Transactions of the American society of Agricultural Engineers, v.35, p.523-533, 1992.

Shull, H.; Dylla, A. S. Wind effects on water application patterns from a large, single nozzle sprinkler. Transactions of the American Society of Agricultural Engineers, v.19, p.501-504, 1976.
Smith, R. J.; Gillies, M. H.; Newell, G.; Foley, J. P. A decision support model for traveling gun irrigation machines. Biosystems Engineering, v.100, p.123-136, 2008.

Solomon, K.; Bezdek, J. C. Characterizing sprinkler distribution patterns with a clustering algorithm. Transactions of the American Society of Agricultural Engineers, v.23, p.899906, 1980.

Tomazela, C. Otimização do uso de um aspersor tipo canhão em função das características operacionais e velocidade média do vento. Piracicaba: ESALQ/USP, 1996. 59p. Tese Doutorado 